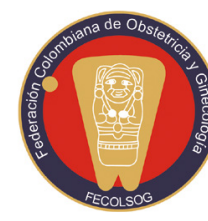

\title{
LA REVISTA COLOMBIANA DE OBSTETRICIA Y GINECOLOGÍA DE NUEVO EN MEDLINE
}

os editores de la Revista Colombiana de Obstetricia y Ginecología (RCOG) tenemos el gusto de comunicarles a los miembros de la Federación Colombiana de Obstetricia y Ginecología (Fecolsog), a los médicos de nuestra especialidad, al personal de salud que trabaja en la salud sexual y reproductiva de la mujer, y a los autores del país y la región que han publicado sus estudios en la RCOG, que la revista ha sido nuevamente aceptada en Medline por el Departamento de Salud y Servicios Humanos de los Estados Unidos, a partir de marzo de 2019.

Esta aceptación no es fortuita, es el resultado de muchos años de trabajo serio y de alta calidad llevado a cabo por el equipo editorial de la revista. Ya habíamos aplicado en dos ocasiones a Medline, la primera en el año 2010 y la segunda en el año 2012. De esta manera ya somos, junto con las revistas Biomédica, Revista de Salud Pública, Colombia Médica y la Revista Colombiana de Psiquiatría, una de las cinco revistas médicas indexadas en la base de datos de la U.S. National Library of Medicine (NLM) de los Estados Unidos. La RCOG había estado indexada en Medline entre 1965 y 1971.

En la carta de aceptación a la RCOG queda claro que deberemos seguir cumpliendo con los estándares de calidad de la NLM y con las mejores prácticas editoriales que hemos venido instaurando desde que asumimos la dirección de la revista. Mantenerse en este sitio de privilegio requiere de un mayor esfuerzo de todas las partes interesadas: de nosotros como editores, para seguir apoyando a los autores a fin de que los estudios publicados cumplan con las expectativas de los lectores y les sean útiles; de los autores, quienes deberán cumplir con los requisitos para la aceptación inicial de los manuscritos por evaluar, como también con las estándares internacionales para publicación por tipo de diseño de estudio, o los formatos de la
RCOG para la publicación de los reportes de caso con revisión de la literatura; para las directivas de la Fecolsog que deberán garantizar los recursos necesarios a fin de mantener una publicación de la más alta calidad, y de los miembros de la Fecolsog quienes comprenderán la importancia de apoyar a la Federación para que pueda continuar con el principal objetivo de la revista: servir de órgano de difusión para la investigación y la educación de nuestros especialistas en el país y la región en pro de una mejor salud de la mujer latinoamericana y del Caribe.

Por último, queremos agradecer a los miembros de las juntas directivas, a los gerentes que nos han acompañado en este esfuerzo en los últimos años, a la gerencia actual, a los comités editorial y científico, a los pares evaluadores, a los autores que han confiado en nuestra revista para publicar sus estudios, y a las personas que conforman el equipo editorial por su esfuerzo, compromiso y dedicación.

La tarea que nos espera es tan grande o mayor que la que hemos concluido con esta aceptación, y a ella nos comprometemos.

Hernando Gaitán-Duarte, MD, MSc

Universidad Nacional de Colombia

Editor

\section{Jorge Andrés Rubio-Romero, MD, MSc FACOG}

Universidad Nacional de Colombia

Editor Asociado

\section{Carlos Fernando Grillo-Ardila, MD, MSc FACOG}

Universidad Nacional de Colombia

Editor Asociado 